\title{
TRANSIÇÃO AGROECOLÓGICA A PARTIR DA FORMAÇÃO TÉCNICA NO ASSENTAMENTO GLEBA XV DE NOVEMBRO EM ROSANA - SP
}

\author{
Flávio Aparecido Pontes ${ }^{l}$ \\ Vera Lúcia Silveira Botta Ferrante ${ }^{2}$ \\ Luis Antônio Barone ${ }^{3}$ \\ Manoel Baltasar Baptista da Costa
}

Resumo: A agroecologia considerada enfoque científico, teórico, prático e metodológico, com base em diversas áreas do conhecimento, se propõe a estudar processos de desenvolvimento sob uma perspectiva ecológica e sociocultural, a partir de um enfoque sistêmico, adotando o agroecossistema como unidade de análise, para apoiar a transição dos modelos convencionais de agricultura para estilos de agricultura sustentável. Neste contexto nosso objetivo foi compreender como foi a trajetória pós-formação e a contribuição dos mesmos seja enquanto técnicos nos assentamentos ou nos lotes familiares dos egressos do curso técnico em Agroecologia da Sala descentralizada no Assentamento Gleba XV de Novembro. Trata-se de uma pesquisa aplicada, de natureza qualitativa e exploratória. Os procedimentos técnicos utilizados foram pesquisa bibliográfica, pesquisa documental e levantamentos. Concluímos assim, que no processo de transformação, do conhecimento e da mudança social, a formação da primeira turma do curso técnico em agroecologia já avançou, transformando por meio de ações e pensamentos, as formas de produção das suas famílias.

Palavras-chave: Agroecologia; Formação Técnica; Educação do Campo; Transição Agroecológica

\footnotetext{
${ }^{1}$ Professor Assistente na área de Gestão do IFSP - Campus de Boituva - Doutorando em Desenvolvimento Territorial e Meio Ambiente na Universidade de Araraquara - UNIARA.

${ }^{2}$ Socióloga, Pesquisadora $1 \mathrm{~A}$ do $\mathrm{CNPq}$, Coordenadora do Programa de Pós-graduação em Desenvolvimento Territorial e Meio Ambiente - UNIARA.

${ }^{3}$ Sociólogo, Professor do Departamento de Geografia da UNESP, Campus de Presidente Prudente.

${ }^{4}$ Professor do Programa de Pós-graduação em Desenvolvimento Territorial e Meio Ambiente - UNIARA.
} 
Abstract: The agroecology considered as a scientific, theoretical, practical and methodological approach, based on several areas of knowledge, proposes to study development processes from an ecological and sociocultural perspective, starting from a systemic approach, adopting the agroecossystem as a unit of analysis, for Support the transition from conventional agriculture models to sustainable agriculture styles. In this context our objective was to understand how the post-training trajectory and the contribution of these were as technicians in the settlements or in the family lots of the graduates of the technical course in Agroecology of the decentralized room in the Settlement Gleba XV of November. It is an applied research, of a qualitative and exploratory nature. The technical procedures used were bibliographic research, documentary research and surveys. We conclude that in the process of transformation, knowledge and social change, the formation of the first group of the technical course in agroecology has already advanced, transforming through the actions and thoughts, the forms of production of their families.

Keywords: Agroecology; Technical Training; Field Education; Agroecologycal Transition

\section{Introdução}

Vários estudos apresentam e analisam o processo de implantação da chamada modernização conservadora ou revolução verde, introduzida no Brasil a partir dos anos de 1960. (RAMOS, 2007; DELGADO, 1985, 2001; GOODMAN et al, 1985; GRAZIANO DA SILVA, 1996; KAGEYAMA et al, 1987). Do ponto de vista da produção, essa modernização conservadora teoricamente cumpriu sua função. A produtividade agrícola brasileira das principais culturas exportáveis, as chamadas commodities agrícolas, figura-se entre as mais altas do mundo. Dados do Ministério da Agricultura, Pecuária e Abastecimento (MAPA) (BRASIL, 2013a) mostram que o Brasil, desde 2010, vem sendo o primeiro exportador mundial de açúcar, café, suco de laranja, carne bovina, tabaco, aves; o segundo em soja; o terceiro em milho e o quarto em carne suína. Os principais destinos eram União Europeia, China, Estados Unidos, Rússia e Japão.

O superávit da balança comercial do país, ou seja, saldo positivo no período decorrente da diferença entre o volume de mercadorias importadas e exportadas foi, em 2016, da ordem de US\$ 47 bilhões graças à exportação de commodities agrícolas (MARCHESINI e RITTNER, 2017) O mesmo relatório do MAPA (BRASIL, 2013a) faz uma comparação entre o ano de 1960 e 2010, destacando que se o Brasil mantivesse a mesma tecnologia de 1960, teria que ter ocupado mais 145 milhões de hectares para ter a mesma produção obtida em 2010.

No ano de 2013 segundo o MAPA, o Brasil se tornou o maior exportador de soja em grãos e as exportações brasileiras de commodities agrícolas somaram valores acima de US\$ 90 bilhões (BRASIL, 2014a). Contudo, como destaca Veiga (2008, p. 200).

(...) a História também nos ensina que grandes sucessos sempre se transformam em excessos quando não são devidamente controlados. Enquanto não forem aperfeiçoados para evitar abusos e inconvenientes, os métodos de produção da dita agricultura moderna serão tão perigosos quanto foram muito antes inúmeros outras formas de produção primária.

A produtividade agrícola brasileira se apresenta em uma curva crescente desde a década de 1960, pós-implantação da revolução verde, cuja proposição era combater a fome, com aumento da produtividade do trabalho e da terra, apoiada na difusão de tecnologias de produção com base em pacotes tecnológicos (ALMEIDA; PETERSEN; CORDEIRO, 2001).

Para Elhers (1999) esse modelo se tornou o padrão de produção, com apoio estatal, que ignorou totalmente a complexidade agrária e ambiental do Brasil. Para Mostafa Habib (2011) esse processo também permeou as diretrizes para pesquisa, educação e extensão rural, promovendo uma modernização que favorecia grandes áreas, uma vez que o objetivo era a produção em grande escala de commodities para exportação e produção de matéria prima e biomassa para indústrias em ascensão no país.

O chamado pacote tecnológico da revolução verde incluindo suas técnicas de produção ainda é hoje ensinado nas escolas tradicionais de agronomia e são amplamente difundidas por agentes extensionistas, que trazem consigo a base de sua formação no método do difusionismo.

De acordo com Saquet (2008) algo comum aos estabelecimentos de ensino é uma resistência por parte dos profissionais, em relação à produção orgânica, tanto de origem vegetal quanto animal. Para o autor, o compromisso com meio ambiente é um dever de todos os profissionais envolvidos com a 
educação. Assinala que esta resistência deve-se provavelmente ao tipo de formação que estes profissionais tiveram.

Nesse contexto, nosso principal objetivo foi compreender como se deu a formação dos egressos da primeira turma do curso de Técnico em Agroecologia, realizado numa escola implantada no assentamento Gleba XV de Novembro, em Euclides da Cunha Paulista (SP), bem como a trajetória pós-formação e a contribuição dos mesmos, seja enquanto técnicos nos assentamentos ou nos lotes familiares. Parte-se do pressuposto de que essa formação técnica permite um processo de transição de sistemas convencionais de produção para sistemas de base agroecológica nos assentamentos da região.

Dentre os principais resultados temos que a primeira turma do curso técnico em Agroecologia da escola Professora Nair Luccas Ribeiro, formou 16 Técnicos em Agroecologia no segundo semestre de 2011, destes 50\% são do sexo feminino e 05 egressos declararam que realizam trabalho técnico junto à família na produção dos lotes.

Dos egressos apenas 01 realiza algum tipo de processamento de seus produtos nos seus lotes e realizam comercialização na feira do município de Rosana (SP). Os demais (11 egressos - 68,75\%) egressos realizam várias outras atividades profissionais, como atuação no comércio, construção civil, monitoria escola, dentre outras atividades sendo que 01 egresso estava desempregado e 01 egressa que está cursando Agronomia na Universidade do Oeste Paulista em Presidente Prudente (SP).

Com relação à renda dos egressos, a grande maioria (11 egressos - 87,5\%) declarou que a composição da renda obtida não advém da atividade de técnico $\mathrm{em}$ agroecologia. As principais atividades produtivas desenvolvidas nos 04 lotes pesquisados e que têm atuação direta dos egressos são gado leiteiro em $100 \%$ dos casos, gado de corte em $75 \%$ dos casos ( 3 propriedades), a produção de hortaliças e frutas para venda e consumo próprio em $75 \%$ das unidades de produção. Embora todas as propriedades agrícolas pesquisadas tenham declarado o uso em algum momento de defensivos químicos, acreditam ainda que estejam produzindo produtos orgânicos.

O reconhecimento de que as famílias por meio dos egressos estão buscando maneiras menos agressivas de produção deve existir, principalmente ao observamos o entorno dos assentamentos de toda a região do Pontal, em sua maioria ladeados por monoculturas convencionais, como a cana de açúcar, fato que dificulta a aplicação de técnicas e práticas de base agroecológica.
AGROECOLOGIA : Suas concepções e a formação técnica no Brasil

Os problemas decorrentes dessa agricultura dita moderna, cujo modelo foi implantado no Brasil pós anos sessenta são claros: uso de agrotóxicos que contaminam as águas e causam problemas de saúde para trabalhadores e consumidores; assoreamento de rios; devastação de matas e manejo inadequado dos solos causando sua degradação; a produção de monocultura, que reduz a biodiversidade, exigindo cada vez mais insumos externos para manter os níveis de produção; pragas cada vez mais resistentes exigindo mais agrotóxicos; o desaparecimento de sementes crioulas, que causa dependência dos produtores, especialmente pequenos, frente a grandes empresas agroindustriais; o uso de adubos e fertilizantes sintéticos, também causando dependência de grandes empresas agroindustriais; dependência de energia não renovável, a exemplo do petróleo e outros impactos negativos (PETERSEN, 2013).

Para LUZZI (2007), desconsiderou-se, em todo esse processo, a força produtiva da agricultura familiar e a sua necessidade de apoio para que essa categoria pudesse se fortalecer. Os agricultores familiares continuaram excluídos e à margem da sociedade, com o agravante de uma desqualificação social dos seus saberes, o que, para a autora, gerou uma intensa erosão do conhecimento tradicional e perda de sua autonomia.

Formas de superação dessas práticas agrícolas predatórias são perseguidas, desde meados dos anos de 1980, por diversas Instituições de Pesquisa, Universidades, Organizações Não Governamentais. "Fontes cruciais para essa investigação são encontradas nas diversas vertentes da chamada agricultura alternativa ou da emergente agroecologia" (VEIGA, 2008, p. 204).

A agroecologia, originalmente, era uma disciplina científica do curso de agronomia, que estudava a dimensão ecológica dos sistemas agrícolas. A associação de práticas agrícolas sustentáveis com o termo agroecologia deu-se pela proximidade de pesquisadores dessa área às suas práticas e, assim, delineou-se, a busca de fundamentação científica para as mesmas (EHLERS, 1999).

A análise da agricultura na agroecologia ocorre a partir da concepção de ecossistema, ou seja, sistema aberto que inclui todos os organismos vivos presentes numa determinada área, os fatores físicos, químicos e biológicos com os quais interagem (MOUSINHO, 2008), além dos fatores sociais e 
econômicos. Para Caporal e Costabeber (2002), a agroecologia é uma ciência que estabelece bases para a construção de estilos sustentáveis de agricultura e de estratégias de desenvolvimento rural sustentável. É descrita como sendo capaz de agregar e articular conhecimentos de diferentes ciências, considerando saberes populares, permitindo a compreensão, análise e crítica do modelo convencional de agricultura, visando a transição para modelos sustentáveis (CAPORAL; COSTABEBER, 2004).

Para Carmo, Comitrê e Fagundes (2009), a Agroecologia é considerada um campo do conhecimento e de investigação científica, capaz de oferecer ferramentas importantes para a intervenção na realidade, ao passo que defendem que uma estratégia metodológica tem potencial para avaliar o efeito das tecnologias sobre os ecossistemas e sobre a sociedade. Sevilla Guzmán (2001) considera a agroecologia como um novo enfoque científico que representa um salto de qualidade na direção à agricultura de base sustentável, com todos seus aspectos multidimensionais e como uma estratégia metodológica de transformação social.

Gomes e Borba (2004), afirmam que a Agroecologia está fundamentada em bases epistemológicas que diferem das ciências tradicionais, congregando, em uma ciência, fatores de complexidade, dúvida, incerteza, a interdisciplinaridade e o reconhecimento dos saberes tradicionais. Para a Associação Brasileira de Agroecologia (ABA), numa concepção bem semelhante à apresentada por Caporal e Costabeber (2002) a agroecologia é uma ciência entendida como:

[...] enfoque científico, teórico, prático e metodológico, com base em diversas áreas do conhecimento, que se propõe a estudar processos de desenvolvimento sob uma perspectiva ecológica e sociocultural e, a partir de um enfoque sistêmico, adotando o agroecossistema como unidade de análise, (visando) apoiar a transição dos modelos convencionais de agricultura e de desenvolvimento rural para estilos de agricultura e de desenvolvimento rural sustentáveis. (ABA, 2014, SP).

Para Wezel et al (2009), o termo agroecologia tem sido utilizado com significados diferentes descrevendo-a como ciência, como movimento e como práticas agrícolas. Para os autores, na década de 1980, a agroecologia era vista como uma prática, especialmente na América Latina, sendo base para um quadro de desenvolvimento agrícola, apoiada pelos ecologistas, agrônomos e etnobotânicos com destaque para países da América Central e o México em especial. Já em 1990, nos Estados Unidos, a palavra agroecologia foi utilizada para expressar ou descrever um movimento, que se apresentava como um novo caminho para a agricultura e as suas relações com toda a sociedade.

Na mesma década, segundo Wezel et al (2009), a pesquisa aproximou o movimento e as práticas da academia. A agroecologia como disciplina cientifica promoveu mudanças para além do agroecossistema, ampliando o olhar sobre o sistema de produção para uma escala maior, ou seja, uma rede não só produtora de alimentos, mas também distribuidora para um grupo de consumidores conscientes da equidade social por trás de seu consumo (GLIESMANN, 2005).

O agroecossistema, segundo Gliesmann (2005), é o lócus da produção agropecuária, podendo ser uma propriedade ou uma parcela desta, compreendido como um ecossistema. Para o autor, o conceito de agroecossistema fornece uma estrutura com a qual é possível realizar análises de sistemas de produção como um todo, incluidos nessa analise sistemas de insumos e produção, bem como as interrelações entre os componentes desses sistemas.

Gliesmann (2005), embasado nos níveis hierárquicos de Odum; Barret (2008) sendo eles: célula, tecido, órgão, sistema de órgãos, organismo, população, comunidade, ecossistema, paisagem, bioma e ecosfera, considera o mais abrangente o ecossistema, uma vez que inclui todos os fatores abióticos do ambiente, bem como as comunidades que ocorrem em determinada área. Para o autor, ocorre dentro do ecossistema uma intricada rede de interações. A equilibrada interação entre esses níveis hierárquicos é o que fundamenta a agroecologia, segundo Mousinho (2008, p 335), que a define como:

Nova abordagem da agricultura fundamentada no equilíbrio do funcionamento dos ecossistemas, em que se adotam práticas ambientalmente saudáveis, sem emprego de produtos ou metodologias que possam afetar este equilíbrio. A agroecologia é voltada ao ambiente e mais sensível socialmente, centrada não só na produção, mas também na sustentabilidade ecológica do sistema produtivo. O uso atual do termo data dos anos 1970, embora sua ciência e suas práticas sejam tão antigas quanto a agricultura Os principais ramos da agroecologia são: agricultura orgânica, agricultura sustentável, agricultura natural, agricultura biológica, permacultura e agricultura biodinâmica. 
Embora Mousinho (2008) aponte o uso do termo agroecologia como recente (1970), defende que a ciência agroecologia e suas escolas (ramos), são tão antigas quanto a própria agricultura. A transição agroecológica é trazida como conceito central na Agroecologia. Para Caporal e Costabeber (2004), ela é um processo gradual e multilinear de mudança das formas de manejo dos agroecossistemas, tendo como meta a passagem de modelos convencionais de produção para estilos de agricultura com princípios e tecnologias de base ecológica. Esses últimos autores ressaltam que a transição, além de implicar na maior racionalização econômico-produtiva, é um processo social, implicando também na mudança de atitudes e valores dos atores sociais em relação ao manejo e conservação dos recursos naturais.

Gliessman (2005) divide em três os níveis fundamentais para a transição do modelo convencional para o agroecológico, sendo eles, racionalização, substituição e redesenho. Na racionalização, busca-se o incremento nas práticas convencionais, como auxilio na redução de inputs externos que, além de onerosos e escassos, causam danos ao ambiente. No segundo nível há a substituição dos insumos e das práticas convencionais, que além do seu alto custo degradam o ambiente, devendo assim ocorrer a troca das técnicas praticadas por outras menos agressivas e que alterem minimamente o ambiente. O terceiro e mais complexo dos três níveis propõe o redesenho do agroecossistema, a partir de um conjunto de processos ecológicos, eliminando as causas dos problemas não resolvidos.

Pode-se criar, assim, dentro de preceitos ecológicos, uma nova realidade para o sistema produtivo das propriedades. Outro aspecto fundamental é o reconhecimento de que a transição agroecológica não se dará de forma linear, ou um passo depois do outro, na ordem aqui apresentada, mas que há uma dialética entre avanços e recuos que é inerente aos processos de mudança social (BRASIL, 2006). Essa transição agroecológica deve ser entendida não apenas como mudança de tecnologias produtivas e sim como uma relação a partir do primeiro nível onde se reduzem os inputs externos e adoção de técnicas e práticas, como o uso de compostagem, adubação verde, interação entre plantas, controle biológico de pragas e doenças, com aplicação de caldas e preparados isentos de defensivos químicos.

A formação de profissionais no assentamento, a partir do paradigma agroecológico, representa uma nova experiência na construção de processos tecnológicos, ecológicos e socioeconômicos importantes para o desenvolvimento de uma agricultura de base ecológica no assentamento
Gleba XV de Novembro. A partir da agroecologia é possível a busca de mudança de paradigma, colocando em prática o modelo onde a sustentabilidade e equidades tornam-se relevantes.

\section{Caminhos da Metodologia}

Trata-se de uma pesquisa aplicada, de natureza qualitativa e exploratória. Os procedimentos técnicos utilizados foram pesquisa bibliográfica, pesquisa documental e levantamento (KAUARK; MANHÃES; MEDEIROS, 2010).

A agroecologia, como destacado, é uma ciência nova e em construção. Para analisar o papel de técnicos em Agroecologia no processo de transição para sistemas agroecológicos, foi necessário primeiramente compreender o tipo de formação obtida por eles na Escola Professora Nair Luccas Ribeiro. Para tal, analisamos o Projeto Político Pedagógico (PPP) do curso, os planos de ensino das disciplinas, além de entrevistarmos 9 docentes da primeira turma, a partir de um roteiro semiestruturado. Esse questionário foi aplicado aos docentes no mês de março de 2014.

A partir da revisão bibliográfica e com os resultados do tipo de formação obtida, foram elaborados questionários contendo perguntas estruturadas e semiestruturadas (apêndice 2), que foram respondidos pelos 16 Técnicos em Agroecologia formados na primeira turma, a fim de verificar a atuação desses técnicos no processo de transição para a agroecologia no Assentamento Gleba XV de Novembro e em sistemas agroecológicos.

Os questionários foram aplicados aos egressos no período de janeiro a julho de 2014, sendo a maioria por entrevista direta, dois deles respondidos e devolvidos por correio eletrônico e um dos questionários respondido via vídeo conferência, utilizando-se a plataforma Skype ${ }^{\circledR}$. A partir da análise dos questionários levantamos que no assentamento Gleba XV e no assentamento Nova Pontal, existem 4 lotes que têm trabalhado de alguma forma a transição Agroecológica com acompanhamento técnico desses egressos. Realizamos visitas a essas quatro propriedades a fim de verificar a atuação desses técnicos, quais técnicas estão sendo utilizadas e de que forma a transição está transcorrendo.

As visitas foram realizadas nos meses de agosto e dezembro de 2014. As famílias assentadas responderam a questionários com perguntas estruturadas e semiestruturadas. Também foi realizada captação de imagens dos lotes para arquivo. No questionário aplicado a essas famílias, foram abordadas 
questões sobre a caracterização e composição familiar, produção e formas de produção, comercialização e renda, aspectos ambientais dos lotes e participação social.

A análise dos resultados quantitativos deu-se a partir da análise dos gráficos e tabelas que foram construídos com dados extraídos dos questionários. Os resultados qualitativos foram trabalhados a partir da narrativa das famílias sobre os principais desafios e perspectivas enfrentadas por esses técnicos em agroecologia no processo de transição para sistemas de produção agroecológicos. Foi realizado a partir das respostas abertas das entrevistas com roteiro semiestruturado, aplicadas aos técnicos egressos, aos docentes, à coordenadora do curso técnico e ao gestor do convênio entre o CPS e a Fundação ITESP.

\section{Resultados e Discussões}

No mês de julho do ano de 2010, a partir de parceria firmada entre o Centro Paula Souza por meio da Escola Técnica Nair Luccas Ribeiro e a Fundação Instituto de Terras do Estado de São Paulo (ITESP), foi inaugurada, no Setor Três do assentamento Gleba XV de Novembro, a sala descentralizada do Curso Médio em Agroecologia da Escola Professora Nair Luccas Ribeiro, visando à formação de Técnicos em Agroecologia. Infelizmente no ano de 2015, o curso técnico em Agroecologia deixou de ser ministrado sendo substituído pelo Curso Técnico em Agronegócios.

O curso técnico em Agroecologia tinha duração de 18 meses com cumprimento de carga horária de 1.200 horas. Inicialmente matricularam-se no curso 45 alunos, todavia, desta primeira turma formaram-se 16 alunos e, em 2014, a terceira turma estava em formação e contava com 21 alunos. O processo de seleção era realizado para alunos que tinham concluído, no mínimo, a primeira série do Ensino Médio, sendo que os ingressantes eram, em sua maioria, moradores do assentamento, todavia já existem alunos oriundos da área urbana e de outros assentamentos que buscavam a formação em agroecologia na sala da Gleba XV de Novembro.

Com base em preceitos agroecológicos, a sala descentralizada em questão tinha por objetivo tornar-se um centro de referência em agroecologia, num dos mais antigos assentamentos da região do Pontal do Paranapanema que visava romper com o paradigma produtivo utilizado há mais de um século na condução da agropecuária regional, todavia, como pudemos ver, a hegemonia do agronegócio foi mais forte mais uma vez. A criação da escola e a formação de profissionais a partir do paradigma agroecológico, representa uma nova experiência na construção de processos tecnológicos, ecológicos e socioeconômicos importantes para o desenvolvimento de uma agricultura de base ecológica no assentamento Gleba XV de Novembro e outros em seu entorno. A partir da agroecologia é possível a busca de mudança de paradigma, colocando em prática um modelo onde a sustentabilidade e equidades tornam-se relevantes.

A primeira turma do curso técnico em Agroecologia da escola Professora Nair Luccas Ribeiro formou 16 técnicos em agroecologia no segundo semestre de 2011. Destes, 50\% são do sexo feminino, a faixa etária dos egressos formados no curso oscila entre 19 e 54 anos de idade.

Ao serem questionados sobre a sua atuação profissional verificamos que nenhum dos egressos atuava como técnico em agroecologia em instituições de Ater ou ONGs ligadas a atividades de extensão ou para outros agricultores familiares, $5(31,25 \%)$ entrevistados declararam que realizam trabalho técnico junto à família na produção dos lotes, destes 2 atuam em outras atividades remuneradas fora da propriedade.

Dos egressos, apenas 1 realizava algum tipo de processamento de seus produtos no seu lote e comercialização na feira do município de Rosana (SP). O processamento é sabido, tende a agregar valor ao produto. A comercialização direta, por outro lado, consiste num pilar importante da agroecologia.

Os demais egressos $(68,75 \%$, ou seja, 11$)$ realizam várias outras atividades profissionais, como atuação no comércio, construção civil, monitoria em escola, dentre outras atividades sendo que um dos egressos estava desempregado, sendo que o último emprego foi como pedreiro na cidade Cuiabá -MT, e outra egressa estava cursando Agronomia na Universidade do Oeste Paulista em Presidente Prudente (SP). O egresso desempregado estava naquele momento residindo no município de Cuiabá - MT.

Dos egressos que atuam nos lotes com as famílias, observamos que as principais atividades produtivas desenvolvidas nos lotes são gado leiteiro em $100 \%$ dos casos, gado de corte em $75 \%$ dos casos e a produção de hortaliças e frutas para venda e consumo próprio em $75 \%$ das unidades de produção. Em apenas um caso há o processamento de produtos como leite, milho e mandioca que são transformados em bolos, como veremos adiante. São, portanto, atividades produtivas semelhantes às dos demais produtores familiares do Pontal do Paranapanema (SP). 
Com relação à renda dos egressos a grande maioria (11 egressos - 87,5\%) declarou que a composição da renda obtida não advém da atividade de técnico em agroecologia. A renda média dos egressos nas mais diversas atividades exercidasera de $\mathrm{R} \$ 800,00$, portanto, valorum poucosuperiora01 saláriomínimo ${ }^{5}$.

Ao serem questionados sobre a sua experiência na implantação de processos de transição para a agroecologia e quais desafios foram enfrentados, a maioria dos egressos afirmou não possuir experiências nesse sentido e apenas 4 egressos afirmaram ter experiência e ainda assim no próprio lote, logo número menor que os 5 que atuavam em seus lotes. Dentre os desafios, mostrar as famílias a possibilidade de uma nova forma de produção é elencado como o maior deles. Esse talvez seja o maior desafio da agroecologia de uma forma geral, seja enquanto ciência nova ou sobre o prisma de sistema de produção. Enquanto ciência, o desafio rebate nas pesquisas acadêmicas realizadas bem como no conteúdo das aulas ministradas, seja nos cursos de nível médio, seja nos cursos universitários.

Ao serem questionados sobre se as pessoas aceitam bem as mudanças propostas para a transição agroecológica, a maioria (14 egressos que correspondem a 87,5\%) respondeu que não, e isso pode confirmar nosso pensamento anterior. Obtivemos respostas como: "Não, dizem nem tudo dá certo (família)." Egressa, 25 anos. Questionados se tiveram alguma dificuldade para colocar em prática os conhecimentos que receberam no curso técnico, a maioria dos egressos disse que sim, como podemos observar nas respostas abaixo:

Sim, muitas, pois os agricultores já estão acostumados a trabalhar da forma convencional então temos bastante dificuldade em estar transmitindo nosso conhecimento (Egressa, 21 anos),

A minha família não acredita na agroecologia (Egressa, 23 anos).

A proposição dessas mudanças é de difícil aceitação, mostrar que é possível produzir de um modo diferente e provar que isso dará certo é o maior desafio para os egressos, principalmente no período de transição onde, por vezes, parte da área deixa de gerar renda para sua adequação. Além disso, como afirma Klanovicz (2012), há também uma questão cultural: ${ }^{5}$ Valor do salário mínimo vigente em 2014 - R \$ 724,00. Decreto 8.166/2013 de 23 de dezembro de 2013 .
Disponível em: http://www.receita.fazenda.gov.br/legislacao/Decretos/2013/dec8166.htm. Acesso em dez
2014 .

A transição da agricultura convencional para a agroecológica não ocorre de uma hora para outra, mas sim, ela deve ser moldada no tempo, enfrentando, muitas vezes a resistência devido à cultura dos agricultores e a visão que eles acabaram criando que é de uma volta aos meios de produzir antigos. Nesse sentido, é necessário mostrar que isso não é verdade e que a agricultura convencional praticada é insustentável ao longo do tempo.

Para além da questão cultural, que já é um tema bastante controverso, há a questão da sucessão e da manutenção dos jovens nos lotes de reforma agrária. Nas palavras de Malagodi e Marques (2007), os jovens assentados da reforma agrária nascem e crescem nos assentamentos, o que é uma experiência forte, com eventos e emoções que contribuem para formação de sua identidade de jovem rural, com a expectativa de ser um agricultor.

Todavia, para os autores, problemas estruturais como falta de transporte, energia, má condições das estradas, acesso à internet, dentre outros geram desequilíbrio entre a produção e o consumo e por sua vez não garantem o sustento familiar e o atendimento às demandas desses jovens. Essa dificuldade de oportunidades culmina, segundo os autores, na migração pela busca da concretização de seus projetos de autonomia.

Silva, Flores e Ferrante (2012), afirmam que é nessa fase (juventude), que surgem questionamentos quanto a permanecer ou não nos lotes e na lida rural, ou se distanciar da família e do campo com interesse no modo de vida das cidades. Conflito que nasce entre a ausência de perspectiva no meio rural, com a pequena chance de obter um trabalho assalariado para o qual não estão qualificados. Para Whitaker (2006), conforme citada por Silva, Flores e Ferrante (2012) as avaliações sobre os assentados por aqueles que desconhecem sua realidade é um engano, e os projetos de assentamentos é que deveriam ser pensados de forma diferente como segue:

[...] acusar os jovens de abandonarem o campo em busca da cidade, como se houvesse uma "força jovem" interior a comanda-los mecanicamente. Na realidade, os projetos de assentamento é que não preveem a continuidade das gerações. (SILVA, FLORES E FERRANTE, 2012, p 291)

Fica clara a posição de Whitaker (2006), de que a permanência dos jovens no campo depende da formulação de políticas públicas que contribuam para o arranjo de ações voltadas à estruturação para produção e comercialização, bem como da organização social desses jovens em todo o processo. Esse v. 20, n.1, $2017 \quad$ RETRATOS DE ASSENTAMENTOS 
conjunto de estruturações pode ser garantir aos jovens e as suas famílias a renda para o lote familiar, vinda do lote onde vivem, bem como propiciar condições de investimentos futuros nos lotes, por meio da produção de base agroecológica, o que melhoraria sua qualidade de vida, reduziria o êxodo dos jovens; tudo isso atrelado a uma melhoria no que tange às condições ambientais locais.

Ao serem questionados sobre seus lotes, se estes eram agroecológicos, se estavam em processo de transição ou se a produção se dava em sistema convencional, apenas 5 egressos declararam estar em processo de transição, os demais $(68,75 \%)$ declararam que a produção se dá em sistemas convencionais.

Questionados se consideram que a formação lhes permite realizar um processo de transição agroecológica no assentamento, $100 \%$ dos egressos responderam sim para a pergunta. Logo, acredita-se que, com a formação, os mesmos se sentem preparados tecnicamente para realizar uma transição. Contudo, não conseguem colocar isso em prática, seja pela resistência da família, seja pela dificuldade de se conseguir resultados econômicos para mantê-los na propriedade ou ainda para atuarem apenas como extensionistas.

Apenas um único egresso formado na escola, quando questionado sobre quais as técnicas utilizadas na busca da transição agroecológica, elencou o cultivo consorciado de hortaliças, o uso de adubação verde e, principalmente, o uso de compostagem de cama de frango, sendo essa a base da produção de milho, mandioca, frutas e usada na horta que abastece a família e cujo excedente é comercializado na feira local. A totalidade dos egressos declarou nunca ter feito um projeto de financiamento ou similar, todavia, $50 \%$ deles ( 8 egressos) se declararam aptos a realizar tal atividade, o que novamente nos remete à formação considerada boa, pelos egressos.

Quanto à questão do processamento ou da agroindustrialização da produção, apenas uma das egressas do curso $(6,75 \%)$ declarou realizar algum tipo de processamento da produção familiar, como a venda de mandioca descascada, processamento de leite, frutas e milho que são comercializados em forma de pães, doces e pamonha, aos sábados à tarde na feira local.

Aos serem questionados sobre como a agroecologia pode contribuir para o desenvolvimento do assentamento e da região, a totalidade dos egressos declarou que acredita que a agroecologia pode contribuir e algumas respostas de como isso aconteceria foram:

Passando informação e tendo alguns agricultores produzindo orgânicos e entregando para os mercados (Egressa, 25 anos).
Sim, com produção orgânica maior para uma qualidade de vida melhor. (Egressa, 50 anos).

Sobre a existência de experiências agroecológicas no assentamento e na região a maioria dos egressos (12) afirmou não haver ou que desconhecem a existência de experiências no assentamento e na região. Para os demais $25 \%$ (4 egressos) há algumas experiências em lotes do assentamento ou outras propriedades fora deste.

Os egressos foram questionados sobre espaços de debates sobre agroecologia e na região, a resposta da totalidade foi de não conhecimento desses espaços. Apenas 01 apontou o espaço da sala da Escola Professora Nair Luccas Ribeiro como palco desses debates. Também foram questionados sobre terem participado do Colegiado de Desenvolvimento Territorial do Pontal do Paranapanema (CODETER). Eles afirmaram não terem conhecimento deste colegiado.

Com relação à presença de atravessadores no assentamento 2 egressos afirmaram desconhecer a atividade desses no assentamento; os demais, $87,5 \%$,confirmaram a presença dos atravessadores na comercialização da produção do assentamento.

Ao serem questionados se faziam algo para evitar a presença do atravessador, todos que responderam que tinham conhecimento da presença destes, afirmaram que, embora saibam e que essa presença seja prejudicial, nada fazem para combater tal prática.

$\mathrm{O}$ quadro de docentes da primeira turma era formado por $55 \%$ de técnicos da fundação ITESP, $22,5 \%$ eram docentes do CPS e os demais $22,5 \%$ foram contratados para suprir as necessidades da sala. Todos os docentes entrevistados afirmaram no momento da aplicação da entrevista que possuíam experiência em docência.

Os docentes elencaram como principal desafio para ministrar as disciplinas a sua própria falta de conhecimento sobre a agroecologia e também foi citada a falta de unidades demonstrativas que contribuíssem na motivação por meio de exemplos concretos.

Questionados se consideravam que a formação técnica desse curso de Técnico em Agroecologia permitiria aos egressos realizarem um processo de transição agroecológica no assentamento, os docentes, em sua maioria (78\%) acreditavam que sim, $11 \%$ responderam que não acreditavam nessa possibilidade e $11 \%$ não souberam responder a essa pergunta.

A respeito do papel destes técnicos na construção de um processo de 
transição agroecológica, dois pontos tiveram destaque nas respostas do corpo de docentes: o aperfeiçoamento da produção na questão ambiental e melhoria da situação econômica por meio da produção.

Um ponto comum nas respostas dos docentes da primeira turma foi que a base do curso para eles estaria calcada na produção livre de agrotóxicos, o que nos remete a questão da formação clássica das faculdades de agronomia e cursos técnicos no país, todos baseados nos pacotes tecnológicos, desconsiderando o enfoque agroecológico, a visão holística e sistêmica, bem como as seis dimensões da sustentabilidade: a ecológica, a econômica, a social, a cultural, a política e a ética (CAPORAL; COSTABEBER, 2002).

\section{Estratégias familiares e sistemas produtivos}

Durante os meses de agosto a dezembro de 2014 realizamos visitas a quatro lotes, sendo três no Assentamento Gleba XV e um no Assentamento Nova Pontal no município de Rosana (SP). Esses quatro lotes foram selecionados e visitados, pois se tratavam de lotes que os egressos indicaram como lotes familiares com emprego de práticas e técnicas visando a transição agroecológica.

As famílias entrevistadas são formadas em média por cinco pessoas. Embora 5 dos egressos tenham declarado que realizavam trabalho técnico junto à família na produção dos lotes, são 4 lotes em função de que, em uma das famílias, há dois egressos da primeira turma formada na escola.

Embora a declaração dos egressos de que realizaram ações nos lotes das famílias na busca da transição, a totalidade das famílias entrevistadas respondeu sim para a pergunta de ser a produção do seu lote e convencional. Como justificativa apresentaram a dificuldade de se produzir sem uso de defensivos e fertilizantes, o que implica na qualidade visual dos produtos.

Podemos inferir que essa resposta, em parte, se dá porque, para essas famílias, o simples uso de algum insumo químico torna seu lote convencional. Todavia, segundo Gliesmann (2005), ao descrever os níveis fundamentais para a transição de um modelo convencional para o agroecológico, o primeiro nível seria a racionalização, ou seja, buscar a redução de inputs externos nos sistemas de produção. Desta forma, consideramos, com base neste autor, que todos os lotes visitados estão em fase de transição do sistema convencional para o sistema agroecológico ou no nível de racionalização.

Cabe ressaltar que a região onde estão instalados os assentamentos Gleba XV de Novembro e Nova Pontal são áreas muito próximas e cercadas por grandes áreas de monoculturas principalmente de cultivo da cana de açúcar.

Para Vigouroux (2011), citado por Nicholls et al (2015), o arroz, batata, milho e trigo representam $60 \%$ das fontes vegetais de alimentação mundial e apenas 14 espécies fornecem cerca de $90 \%$ da proteína animal consumida mundialmente. Os autores consideram que as extensões de terras cultivadas têm tido crescimento em todo o mundo, sendo que, dos 1,5 bilhões de hectares de terras aráveis, $80 \%$ estão dedicados a alguma monocultura.

Diante das afirmações das famílias, de que sua produção é convencional dada à necessidade do uso de defensivos em alguns momentos, com base nos estudos de Nicholls et al (2015), afirmamos a dificuldade de se produzir sem o uso de defensivos uma vez que as famílias estão cercadas pelas monoculturas, que recebem sistematicamente aplicações de defensivos, o que torna as áreas refúgios de insetos e outros vetores de doenças.

No que tange à produção animal dos lotes, a produção de leite está presente em $100 \%$ destas famílias estudadas e o gado de corte presente em 50\% dos casos. Outros animais como suínos, aves e frangos constituem a produção animal dessas famílias contribuindo para o autoconsumo e incremento da renda pela venda dos animais ou venda de produtos como ovos e frangos.

Vale ressaltar que, para Chayanov (1974), a renda de autoconsumo gerada pelo núcleo familiar, no contexto do balanço-trabalho-consumo, é uma importante referência e deve ser entendida como "tudo aquilo" que a família consome de sua própria produção, ou seja, "tudo aquilo" que não precisa ser adquirido fora da propriedade.

O leite é o principal produto de origem animal na composição da renda das famílias entrevistadas. A produção média das famílias era de 49 litros/ dia entregues a laticínios da região, recebendo valores entre $\mathrm{R} \$ 0,73$ a $\mathrm{R} \$$ 0,93 por litro 6 . Foi possível observar que a família cuja produção era a menor embora seus vizinhos recebessem pelo litro $\mathrm{R} \$ 0,93$, recebia apenas $\mathrm{R} \$$ 0,83 pelo litro entregue, diferença determinada pelo atravessador que é o único que retira o leite em pequena quantidade para conduzir ao resfriador, levando consigo, nessa simples operação, quase $12 \%$ do preço pago pelo leite. Para que o leite seja resfriado, a família ainda paga, por litro, o valor de $\mathrm{R} \$ 0,03$, para cobrir despesas com energia e manutenção do resfriador.

Constatamos que todas as famílias pesquisadas usam produtos químicos e medicamentos no manejo do gado, como vermífugos e tratamentos para

${ }^{6}$ A média Brasil de litro de leite pago por laticínio, sem contabilizar o frete, era, em dezembro de 2014, d e R\$ 0,8935 1. Disponível em http://www.cepea.esalq.usp.br/leite/?page=164. Acesso em fev 2015. 
ectoparasitas, antibióticos dentre outros. O uso de extrato de folhas de Neem (Azadirachta indica) tem sido usado por 1 família entrevistada e, segundo as declarações, tem contribuído significativamente na redução do ataque de carrapatos (Ripicephalus Boophilus microplus), mosca do chifre (Haematobia irritans), bicheiras (Cochliomyia hominivorax) e bernes (Dermatobia hominis). O uso de fitoterápicos nos animais, segundo a família, barateia o custo de produção e torna mais saudável a carne os ovos e demais produtos de origem animal.

Duas famílias entrevistadas possuem capineira formada nos lotes com cana ou capim Napier. As áreas médias de capineira são de 2 hectares e 2 tem os pastos divididos em piquetes, apenas uma das famílias possui capineira piquetes,sendo a única a corrigir o solo das pastagens. Faz-se o uso de calcário dolomítico conforme a disponibilidade financeira da família para esse fim. O uso do rotacionamento nos piquetes se dá de forma aleatória, muito em função da altura do capim, o que empiricamente é utilizado para definir o momento em que o rebanho deve sair de um piquete para o outro.

A produção agrícola das famílias é bem diversificada. São produzidas frutas, verduras, legumes e produtos florestais. Dentre a produção agrícola das famílias há destaque para a mandioca, o milho e o feijão presentes em $100 \%$ dos casos; a produção de frutas está presente em apenas 3 dos lotes (frutas de pomares caseiros). É importante salientar que o Programa de Aquisição de Alimentos (PAA) possibilitou a abertura de canais de comercialização até então inexplorados por esses produtores e lhes permitiu comercializar itens que, devido à pouca produção, eram usados apenas para autoconsumo das famílias e vizinhos ou ficavam perdidos nos quintais.

Contudo, ao serem questionados sobre os preços pagos pelo PAA e pela frequência de entrega dos seus produtos ao programa, obtivemos as seguintes respostas: "entrego mais frutas quando sobra e verduras da horta, mas há uma demora em receber, às vezes não compensa" (Assentada, 51 anos)". E, "Parei de entregar, minha produção é pouca, não compensa" (assentada, 50 anos).A produção de verduras e legumes presente em 3 lotes das famílias também utiliza o PAA como principal canal de comercialização, apenas uma família leva seus produtos para vender na feira no município de Rosana. Essa feira acontece sempre aos sábados, ao entardecer.

As famílias foram perguntadas sobre tratos culturais e sobre técnicas empregadas em suas lavouras. Aferimos que nenhuma das famílias realiza em suas culturas qualquer tipo de controle biológico de pragas ou doenças, duas delas afirmaram fazer uso de fertilizantes químicos nas culturas. Todos os entrevistados declararam que utilizam defensivos químicos em algum momento de sua produção agropecuária. Quando questionados se tinham conhecimento do que era adubação verde, todos os entrevistados afirmaram que sim sabiam, sendo que duas já haviam feito em seu lote e uma faz. Sobre as vantagens e dificuldades afirmaram que os obstáculos se sobressaem, o que os faz optar por outras formas de adubação. "É bom pelo baixo custo, mas, o resultado não é bom e dá muito trabalho." (assentada, 51 anos). Essa afirmação pode justificar um maior uso da compostagem como fonte de nutriente para as culturas. Constatou-se que duas famílias fazem uso desse tipo de material sendo que um utiliza a compostagem adicionada de cama de frango adquirida em granjas da região. Inferimos que esse tipo de adubação é utilizado em culturas como amendoim, feijão, milho, nas hortas e nos pomares

Quando questionados sobre a realização de pousio nas áreas destinadas às lavouras uma família declarou que faz, deixando uma determinada área parada por período de aproximadamente um ano, quando torna a preparála para realizar o plantio. Sobre o uso de rotação de culturas, também um entrevistado afirmou que faz a rotação, plantando milho, seguido de feijão e depois legumes, como abóboras, berinjelas ou batata doce. A consorciação entre as culturas também estava presente em uma propriedade do grupo, principalmente na horta, onde são realizados consorciamento de legumes como abóboras, quiabo e pimentas e também de folhas como alface, almeirão, couve e cheiro verde.

Com relação às sementes utilizadas para o plantio, todos os produtores entrevistados declararam que parte é produzida no próprio lote e parte adquirida em lojas especializadas. As principais sementes produzidas nos lotes são as de abóboras, milho, quiabo, pimentas, maracujá e feijão. Já sementes como amendoim e a maior parte das hortaliças são adquiridas no comércio e todas produzidas em sistema convencional.

Quando questionados se a formação do técnico em agroecologia trouxe alguma melhoria para a produção e, consequentemente, contribuiu para melhorar a qualidade de vida da família, 3 famílias $(75 \%)$ responderam positivamente.

Com relação à melhoria na qualidade e na quantidade de alimentos consumidos pela família, houve um equilíbrio: 2 afirmando que sim e 2 que não. Apenas 1 das famílias afirmou que a renda teve melhoria, atribuindo 
essa melhora à economia com insumos que deixaram de ser comprados, em vista do aproveitamento de materiais disponíveis no lote.

Observamos a confusão conceitual que citamos anteriormente entre a agroecologia e a produção orgânica nas declarações anteriores. Embora todas as famílias tenham declarado o uso em algum momento de defensivos químicos, acreditam ainda que estejam produzindo produtos orgânicos. O reconhecimento de que estão buscando maneiras menos agressivas de produção deve existir, principalmente ao observamos o entorno dos assentamentos de toda a região do Pontal, em sua maioria ladeados por plantações convencionais de cana de açúcar como já dissemos anteriormente. Esta proximidade implica em assédios a parcerias baseadas em assimetrias ou em arrendamentos.

Diante de todas essas dificuldades e contratempos, ainda que em pequeno grau, é perceptível que, conforme os níveis preconizados por Gliessman (2005), a diminuição de inputs externos ocorre e, assim, a transição agroecológica vem acontecendo nos lotes, fruto da formação desses egressos, atrelada ao conhecimento empírico de suas famílias e aos seus valores tradicionais.

\section{Conclusões}

Dificilmente há conclusões consensuais quando são discutidas experiências de transições agroecológicas. Há divergências sobre o momento de definição deste processo. Há bloqueios decorrentes de resistências advindas dos grandes complexos agroindustriais ferrenhos defensores da agricultura convencional. Há expressões de sustentabilidade em experiências pequenas, mas expressivas nas demonstrações da melhoria da qualidade de vida. Há controvérsias, o que fortalece a necessidade dos pesquisadores se debruçam sobre situações de transição agroecológicas. Foi esta a intenção deste artigo que elegem a formação técnica em Agroecologia como elemento presente nesta trama.

A formação técnica em agroecologia da primeira turma na sala descentralizada da Gleba XV, objeto deste artigo simboliza apenas o primeiro passo. Os egressos representam a possibilidade de mudança dos aspectos tecnológicos, ecológicos e socioeconômicos do assentamento rumo a uma agricultura mais sustentável. A sua formação, enquanto esse primeiro passo, ainda tem muito a percorrer.

Se comparados aos desbravadores em busca de algo, veremos que a primeira turma formada teve grandes dificuldades durante sua formação e pós-formação técnica. Essas dificuldades em parte se devem às questões estruturais da escola e na formação dos docentes, que não estavam aptos a trabalhar, em um contexto tão amplo, como o terreno da agroecologia, essa dificuldade foi expressa pelos próprios docentes conforme Pontes (2015).

Embora o Projeto Político Pedagógico (PPP) do curso defina o perfil do Técnico em Agroecologia como sendo o profissional que atua em sistemas de produção agroecológico: planeja e executa projetos e atividades de preservação dos recursos hídricos, do solo, da fauna e da flora silvestre; orienta sobre o controle natural e biológico dos insetos, doenças e plantas espontâneas; realiza atividades de educação ambiental, de gestão da propriedade agroecológica; promove a integração e a organização social; utiliza de técnicas e tecnologias de conservação e armazenamento da matéria-prima e do processamento dos produtos agroecológicos.

O perfil técnico do profissional conforme o PPP do curso integra as dimensões da sustentabilidade como vimos anteriormente segundo Caporal e Costabeber (2002). A formação diferenciada das escolas tradicionais adotada na sala descentralizada pode romper com olhar preconceituoso e negativo sobre o campo conforme descrito por Arroyo, Caldart e Molina (2004), bem como, Valorizar conforme descreveu Souza (2007), uma nova concepção de práticas sociais. Onde o campo permite novas possibilidades de reprodução social, organização social das comunidades e desenvolvimento sustentável, atrelados a um mercado que alie a produção e o consumo conscientes.

Com relação a sua atuação profissional no mercado de trabalho, há uma resistência na contratação destes profissionais, especialmente pelas indústrias sucroalcooleiras que pautam sua produção basicamente por pacotes tecnológicos, por outro lado agricultores familiares geralmente descapitalizados não conseguem pagar pelos serviços técnicos. Aos egressos que conseguiram trabalhar seus conhecimentos nos próprios lotes familiares, se apresentam um conjunto de desafios.

Dentre os desafios, mostrar para as famílias a possibilidade de uma nova forma de produção é elencado como o maior deles, pois e perpassa por uma mudança paradigmática, a troca de um modelo arraigado e já tradicional para um modo de produção diferente em que pese o respeito entre a relação homem natureza e ainda seja capaz de propiciar renda que garanta o sustento da família e atenda aos anseios desses jovens.

As atividades exercidas fora da área de formação técnica, dos egressos da 
primeira turma nos dão indícios de que essa formação não conseguiu fazer com que as mudanças pudessem ocorrer em tão pouco tempo, nem mesmo evitou o êxodo desses egressos na busca de melhores condições nas cidades. Fato que é corroborado pelos egressos que permaneceram nos lotes, mas enfrentam dificuldades para aplicar o processo de transição agroecológica frente à resistência familiar.

Sobre essa resistência, há de se fazer ressalvas. Trata-se de uma resistência cultural, afinal, a forma com que essas famílias vêm produzindo ocorre há vários e vários anos, sendo transmitida muitas vezes como herança pelos pais e avós. Com a formação desses jovens, formação essa que prima pela mudança para um sistema produtivo diferente de tudo aquilo que seus familiares conhecem e realizam, é compreensível que haja algumas preocupações e resistências, afinal à renda e o sustento depende do que a família produz.

Essa preocupação e resistência acabam frustrando os egressos, que vão em busca de outras opções, principalmente nas cidades (comércio/construção civil), já que a formação técnica também não contribui para inserção desses egressos como técnicos em empresas da região, uma vez que sua formação não segue os padrões de produção que são utilizados por essas empresas, em especial as usinas do setor sucroalcooleiro, guardiãs do modelo convencional de desenvolvimento.

Se pensarmos na grande maioria dos agricultores familiares brasileiros, esses não têm recursos para a contratação de técnicos. Cabe ao Estado pensar numa forma de absorver esses técnicos em agroecologia para formação de quadros técnicos dentro dessa nova concepção.

Consideramos que, quanto ao êxodo, três problemas precisam ser revistos. Primeiro, a lógica de produção dos assentamentos rurais atrelada à maneira de produzir de grandes produtores (agronegócio) não funciona em face da multidimensionalidade presente dentro de cada família e cada unidade de produção (lote). Segundo, uma série de problemas estruturais como grandes distâncias entre o lote/produção e seu consumidor, estradas ruins, falta de comunicações, falta de água, atravessadores, enfim todo um conjunto problemático que ainda atinge os agricultores familiares sejam eles assentados ou não, problemas que diminuem consideravelmente sua renda, dificultam o escoamento de sua produção, causam prejuízos e custos elevados no transporte/comercialização.

O terceiro, e talvez o mais grave, uma vez que limita as perspectivas dos egressos e demais jovens assentados é a questão da sucessão nos lotes. Se considerarmos um lote médio de 10 hectares por família assentada, onde há por família dois ou três filhos, como esses poderão no futuro continuar vivendo ali e com renda suficiente, que garanta o sustento dos pais e das futuras famílias a serem constituídas pelos seus filhos? Ora se os egressos têm passado com a família dificuldades que os forçam, a buscar novas fontes de remuneração fora dos lotes para o atendimento de suas necessidades, conseguirão os egressos enxergar futuro com qualidade de vida no assentamento? Se o lote não comportar toda a família e os seus futuros agregados, poderão ter outro lote e, assim, perpetuar a sua identidade de agricultor? Problemas se desdobram nesta realidade multidimensional.

Como afirmamos, sendo a formação técnica em agroecologia desses egressos o primeiro passo, a sua caminhada apresentou um pouco mais de dificuldades, características do pioneirismo. Todavia, quando refletimos sobre o conjunto de respostas das famílias, fica evidente que as famílias acreditam na agroecologia, embora tenham certo receio. Ficou perceptível que uma série de mudanças de pensamentos, principalmente entre a forma de produzir e a forma de enxergar o lote muda a pós a formação da primeira turma, o que remete a conclusão de que a formação desses jovens já contribuiu para que ocorresse uma ruptura com a forma de produção: há uma busca pela substituição de insumos e o uso de defensivos tem sido apenas nos casos em que há o risco do comprometimento da safra, como uma forma de "salvar a lavoura" literalmente, e não mais como um método comum aos plantios dos lotes. A conscientização ambiental face aos problemas já é uma clara demonstração de que a formação desses egressos tem contribuído para mudanças no assentamento Gleba XV de novembro.

Deixamos assim duas sugestões para que essa formação possa ser, a nosso ver, mais efetiva e eficaz. A primeira diz respeito à articulação social/ política dos egressos e a segunda diretamente à relação produção/comercialização. Por meio da parceria com a Fundação ITESP e Centro Paula Souza, poderiam ser articuladas ações e criados instrumentos que fomentassem, a partir da escola técnica, espaços de debate sobre a agroecologia e que incentivassem uma melhoria na participação social e política desses egressos nos espaços do assentamento (associações e cooperativas). A partir da escola poderiam também mobilizar os egressos para que participassem junto às associações e cooperativas, bem como, em outros espaços possíveis na construção de novos mercados, ou mesmo pelos canais já existentes como o PAA e PNAE. 
Assim, estimular esses egressos e produtores para que, além da entrega de seus produtos in natura, possam estimular outras opções de beneficiamento simples capazes de agregar valor aos seus produtos, como o simples descascamento e embalagem de produtos que seriam entregues diretamente aos consumidores finais, gerando circuitos curtos entre a produção e o consumo final, o que é preconizado pela agroecologia.

Esse conjunto de ações-produção de base agroecológica, transformação de produtos nos lotes e entregues diretamente aos consumidores, que também devem estar conscientes da importância dessa produção mais saudável com a comercialização a preços justos podem transformar a concretude desses egressos e do assentamento. Destacamos o texto de Ayukawa (2005), no qual afirma:

[...] a possibilidade de ser a Agroecologia uma maneira de se trabalhar a vida no seu cotidiano, tomando cuidado para não cair no senso comum e considerando que o conhecimento que irá se formar será sempre passível de rupturas, ou seja, aquilo que se vê no início sempre será diferente do seu resultado final.

Concluímos, assim, que no processo de transformação, do conhecimento e da mudança social a formação da primeira turma do curso técnico em agroecologia já avançou deixando mais do que apenas o primeiro passo inicial da longa caminhada. Todavia, com a troca do curso na sala descentralizada em 2015 pelo curso técnico em agronegócios representa um retrocesso sobre a mudança de paradigma que poderia fortalecer a forma de produção no assentamento e seu entorno.

\section{Referências Bibliográficas}

ALMEIDA, S. G.; PETERSEN, P; CORDEIRO; A., A Crise Socioambiental e Conversão Ecológica da Agricultura Brasileira: subsídios à formação de diretrizes ambientais para o desenvolvimento agrícola. Rio de Janeiro: AS-PTA, 2001.

ARroyo, M. G.; CALDART, R. S.; MOlinA, M. C. (Orgs.). Por uma Educação do Campo. Petrópolis: Vozes, 2004

ASSOCIAÇÃO BRASILEIRA DE AGROECOLOGIA. Estatuto Da
Associação Brasileira De Agroecologia. Disponível em: http://abaagroecologia.org.br/wordpress/wp-content/uploads/2013/06/Estatuto-ABA.pdf. Acesso em: jul. 2014.

ASSOCIAÇÃO DE AGRICULTURA ORGÂNICA. O que é a agricultura orgânica. Disponível em: http://aao.org.br/aao/agricultura-organica. php Acesso em: mai 2014.

BRASIL. Banco Central do Brasil. Manual de credito rural do Pronaf, 2011 Disponível em http://www3.bcb.gov.br/mcr/. Acesso em: jul. 2013.

BRASIL. Câmara Interministerial de Agroecologia e Produção OrgânicaCIAPO. Plano Nacional de Agroecologia e Produção Orgânica PLANAPO. Brasília, DF: MDS; CIAPO, 2013b. Disponível em http://www. mda.gov.br/sitemda/sites/sitemda/files/user_img_19/BrasilAgroecologico_Baixar.pdf. Acesso mar 2014.

BRASIL. Decreto $\mathbf{n}^{\mathbf{0}}$ 7.794, de 20 de agosto de 2012. Institui a Política Nacional de Agroecologia e Produção Orgânica - PNAPO. 2012. Disponível em http://www.planalto.gov.br/ccivil 03/_ato2011-2014/2012/decreto/d7794.htm. Acesso em mar 2014.

BRASIL. Estáticas da produção brasileira. Ministério do desenvolvimento Industria e Comercio Exterior, 2014 a. Disponível em: http://www.mdic.gov. br/sitio/interna/index.php?area=5. Acesso em: mar. 2014.

BRASIL. Instituto Brasileiro de Geografia e Estatística. Censo Demográfico 2010: Dados do senso disponível em: http://www.ibge.gov.br/home/ estatistica/populacao/censo2010/default.shtm acesso em jul 2014.

BRASIL. Marco Referencial em Agroecologia. Empresa Brasileira de Pesquisa Agropecuária: Brasília, DF. Embrapa Informação Técnica, 2006, 70p. Disponível em http://www.alice.cnptia.embrapa.br/bitstream/doc/107364/4/ Marcoreferencial.pdf. Acesso em abril de 2014.

BRASIL. Portaria $\mathbf{n}^{\mathbf{0}} \mathbf{1 . 2 5 8}$, de 2007. Criação da Comissão Nacional de Educação no Campo. Ministério da Educação. 
CAPORAL; F. R.; COSTABEBER, J. A. Agroecologia: enfoque científico e estratégico para apoiar o desenvolvimento rural sustentável (texto provisório para discussão). Porto Alegre: EMATER/RS-ASCAR, 2002. (Série Programa de Formação Técnico-Social da EMATER/RS Sustentabilidade e Cidadania, texto 5)

CAPORAL, F. R.; COSTABEBER, J. A. Agroecologia: alguns conceitos e princípios. Brasília: MDA/SAF/DATER-II CA, 2004.

CARMO; M. S., COMITRE; V., FAGUNDES; G., Agroecologia e transição agroecológica: termo de referência. Seminário Criação da Rede de agroecologia da Unicamp, FEAGRI - Unicamp, Campinas 2009. Disponível em: http://www.cisguanabara.unicamp.br/redeagroecologia/arquivos/biblagroecologia/ termodereferencia.pdf. Acesso em: mar. 2014.

CHAYANOV, A. V. La Organizacion de La Unidade Económica Campesina. Instituto de Investigación Cientifica de Economia Agricola de Moscú, y publicado por la Cooperativa Editora, Moscú. 1925. Reeditado por: Ediciones Nueva Vision. Buenos Aires. 1974.

DELGADO, Guilherme. Capital Financeiro e Agricultura no Brasil. São Paulo: Ícone e UNICAMP, 1985.

EHLERS, E. Agricultura Sustentável: Origens e perspectivas de um novo paradigma. São Paulo: Livros da Terra, 1999.

GLIESMANN; S. R. Agroecologia: processos ecológicos em agricultura sustentável. UFRGS: Porto Alegre, 2005

GOODMAN, D. E; SORJ, B; WILKINSON, J. Agroindústria, políticas públicas e estruturas sociais rurais: análises recentes sobre a agricultura brasileira. Revista de Economia Política. vol 5, n 4, out.dez 1985, pp $31-56$.

GRAZIANO DA SILVA, José. A nova dinâmica da agricultura brasileira. Campinas: UNICAMP/IE, 1996.
KAGEYAMA, A. O Novo Padrão Agrícola Brasileiro: do Complexo Rural aos Complexos Agroindustriais. Campinas; UNICAMP, 1987.

KAUARK; F, MANHÃES; F. C. E; MEDEIROS; C. H. Metodologia da Pesquisa: guia prático. Itabuna: Via Litterarum, 2010.

KLANOVICZ, J. Agricultura com base Agroecológica para uma Ética Ambiental e o Desenvolvimento Sustentável, 2012. Centro Nacional de Educação a Distância. Disponível em: http://www.cenedcursos.com.br/agriculturabase-agroecologica-etica-ambiental-desenvolvimento-sustentavel.html. Acesso em: dez 2014.

LELIS; A. Necessidade das intervenções: Extensão Rural como serviço ou como direito? Interações. Campo Grande, v. 13, n. 1, p. 69-80, jan./jun. 2012.

LUZZI; N., O debate agroecológico no Brasil: uma construção a partir de diferentes atores. Tese (Doutorado em Desenvolvimento, Agricultura e Sociedade). Universidade Federal Rural do Rio de Janeiro, Instituto de Ciências Humanas e Sociais, Rio de Janeiro: UFRRJ, 2007.

MALAGODI, E.; MARQUES, R. Para além de ficar ou sair: as estratégias de reprodução social dos jovens em assentamentos rurais. In: CARNEIRO M. J.; CASTRO E. G. (Orgs.). Juventude rural em perspectiva. Rio de Janeiro: Mauad 2007. pp. 197-214

MARCHESINI L., RITTNER D., |Balança comercial fecha 2016 com o maior superávit desde 1980 disponível em: http://www.valor.com.br/ brasil/4823024/balanca-comercial-fecha-2016-com-o-maior-superavitdesde-1980 acesso em março de 2017.

MOSTAFA HABIB; M. E. D., Agricultura brasileira é deficiente. Revista do Instituto Humanitas. Unisinos, edição 368, São Leopoldo, 2011.

MOUSINHO, P.. Glossário. In: TRIGUEIRO, André (coord). Meio Ambiente e no século 2121 especialistas falam da questão ambiental nas suas áreas de conhecimento. 5. Ed. Campinas, SP: Armazém do Ipê (Autores 
Associados), 2008.

NICHOLLS, C. et al. Agroecologia e o desenho de sistemas agrícolas resilientes às mudanças climáticas. Agriculturas. Cadernos para debate, $\mathrm{n}^{\circ} 2$, jan 2015. Disponível em http://aspta.org.br/wp-content/uploads/2015/02/ Agriculturas_Caderno_DebateN02_Baixa.pdf. Acesso em fev 2015.

ODUM, E. P.; BARRET. G. W. Fundamentos de Ecologia. Cengage Learning, São Paulo, 2008, 612p

PETERSEN; P. Agroecologia e a superação do paradigma da modernização. In: NIERDELE; P. A., ALMEIDA; L., VEZZANI F. M., Agroecologia: práticas, mercados e políticas para uma nova agricultura, Kairós Edições: Curitiba, 2013.

PONTES, F. A.; PEREIRA, E. L.; SILVA, A. A., FAVARIN; S. Panorama da cadeia produtiva da acerola no município de Junqueiropólis. In: $4^{\mathrm{a}}$ SIMPÓSIO NACIONAL DE TECNOLOGIA EM AGRONEGÓCIOS. 2012, Mogi das Cruzes (SP). Anais... Mogi das Cruzes, 2012.

RAMOS; P., Referencial teórico e analítico sobre a agropecuária brasileira. In: RAMOS; P., et al (org). Dimensões do agronegócio Brasileiro: políticas instituições e perspectivas. NEAD Brasília, 2007.

SAQUET, A. A. Reflexões sobre a agroecologia no Brasil. In: ALVES, A. F. et al (org). Desenvolvimento territorial e agroecologia. Expressão Popular: São Paulo, 2008.

SEVILLA-GUZMÁN, E.. As bases sociológicas da agroecologia. In: ENCONTRO INTERNACIONAL SOBRE AGROECOLOGIA E DESENVOLVIMENTO RURAL SUSTENTÁVEL, 2001, Botucatu (SP). Anais... Faculdade de Ciências Agronômicas, Unesp, 2001.

SILVA; S. FLORES; A.F. FERRANTE V.L.B Entre flores e espinhos: A situação da juventude em duas regiões do estado de São Paulo in Retratos de assentamentos v 15 n. 01,Nupedor/Uniara, Araraquara, 2012.
SOUZA; S. P. Assentamentos rurais e novas dinâmicas socioeconômicas: O caso dos municípios de Rosana, Euclides Da Cunha Paulista e Teodoro Sampaio - SP. 2007. Dissertação (Mestrado em Geografia). Faculdade de Ciências e Tecnologia, Unesp, Presidente Prudente, 2007.

VEIGA; J.E., A agricultura no mundo moderno: diagnóstico e perspectivas. In: TRIGUEIRO, A. (org). Meio ambiente no século 21: 21 especialistas falam da questão ambiental nas suas áreas de conhecimento. 5 ed. Campinas: Armazém do Ipê, 2008.

VIGOUROX, J. B Biodiversity, evolution and adaptation of cultivates crops. compto rendle biologius 33: 450-457, 2011

WEZEL, A.; et al. Agroology as a science, a movement and a practice. A review Agronomy. Sustainble. Develepoment. INRA, EDP Sciences, 2009.

WHITAKER,D.C.A, SOUZA, M. F. A Permanência dos jovens nos assentamentos de reforma agrária: um rosário de equívocos. Revista retratos de assentamentos, n10 2006, Nupedor/Uniara, Araraquara,2006. 